\title{
Angiographic Estimation of Culprit Vessel Disease Severity in Acute ST-Segment Elevation Myocardial Infarction after Thrombolysis
}

\author{
Ahmed W, ${ }^{1}$ Noon MJ, ${ }^{1}$ Haq A, ${ }^{1}$ Mustafa B ${ }^{2}$ \\ 'Shifa College of Medicine, Islamabad, Pakistan, ${ }^{2}$ Department of Cardiology, Shifa International Hospital, Islamabad, \\ Pakistan.
}

\section{ABSTRACT}

Introduction: To study the angiographic disease severity of the infarct vessel after thrombolysis in patients with acute ST-elevation myocardial infarction and their 90 days outcome.

Methods: We conducted a retrospective analysis of a prospectively maintained cardiology database at Shifa International Hospital from February 2011 to August 2011. A total of 57 patients who underwent thrombolysis for acute ST elevated Myocardial Infarction and subsequent coronary angiographies within 24 hours of hospitalization were studied. Angiographic disease severity in the infarct vessel was quantified as mild $(<50 \%)$, moderate $(50-70 \%)$, severe $(70-99 \%)$ and total occlusion $(100 \%)$. Secondary outcomes of recurrent ischemia/reinfarction, target lesion revascularization and death were also assessed at three months follow up.

Results: Thrombolysis was successful in 48 patients. All nine cases of failed thrombolysis underwent rescue PCI. Mean time of catheterization from thrombolysis was $16 \pm 4$ hours. Total 56 (98.2\%) patients had severe $(>70 \%)$ and 1 patient had moderate $(50-70 \%)$ angiographic disease of the infarct vessel. Left anterior descending artery was the infarct vessel in $32(56 \%)$ cases and right coronary artery in 20 (35\%). Total 15 (26\%) patients had double vessel and 11 (19\%) had triple vessel coronary artery disease. Percutaneous coronary intervention was performed in all patients using bare metal stents or drug eluting stents. At three month follow-up, only one patient had recurrent myocardial infarction due to stent thrombosis.

Conclusions: The overwhelming majority of patients presenting with ST elevation myocardial infarction have angiographic evidence of severe underlying disease in the infarct vessel despite clinically successful thrombolysis.

Keywords: acute coronary syndrome; coronary angiography; myocardial infarction; thrombolysis.

\section{INTRODUCTION}

In the 1980's a few small scale retrospective angiographic studies by a group led by Ambrose et al suggested that acute myocardial infarction occurred more frequently in coronary arteries with less than 50\% plaque stenosis. ${ }^{1,2}$ The same group of investigators also proposed the idea of plaque disruption and subsequent thrombosis as the underlying mechanism in patients presenting with acute coronary syndromes (ACS) i.e. STsegment elevation myocardial infarction (STEMI), nonST-segment elevation myocardial infarction (NSTEMI) and unstable angina (UA). ${ }^{3}$ While the initial observation

Correspondence: Muhammad Jawad Noon, Shifa College of Medicine, Pitras Bukhari Road, H-8/4, Islamabad, 44000, Pakistan. Email: jawadnoon@gmail.com, Phone: +923336390754. 
of plaque disruption and thrombosis has now been well validated and accepted as the main mechanism behind acute coronary syndromes, the limited initial observation of less than $50 \%$ culprit vessel stenosis remained largely unvalidated. The large scale use of routine coronary angiography in the late 1990's and early 2000's provided more robust angiographic data in patients with ACS. Several large scale prospective studies in the last decade including recent studies using fractional flow reserve have challenged the initial observations of mild to moderate disease severity in culprit vessel and have clearly shown that underlying disease severity is the most strong predictor of subsequent coronary events. ${ }^{4-6}$ We sought to evaluate the degree of underlying coronary artery disease in our patient population of acute STEMI undergoing thrombolysis. To our knowledge, this is the first such published data from South Asia.

\section{METHODS}

A retrospective study was conducted from a cardiology database of Shifa International Hospital from February 2011 to August 2011. The study was approved by our hospital ethical committee. This data base is comprehensive software which includes all patients admitted with ACS under the cardiology service. Detailed information including demographics, baseline characteristics, admission medications, non-invasive imaging, coronary artery disease (CAD) extent on coronary angiography and intervention, in hospital complications, discharge medications and long term follow-up are recorded. For the present study, all patients presenting with STEMI and treated with thrombolysis were included. Decision to use the type of thrombolytic drug was based on the consent of the patient. Standard definitions of acute coronary syndrome, ST elevation myocardial infarction, Non ST elevation myocardial infarction and unstable angina were used. Dyslipidemia was defined as serum triglycerides $>200 \mathrm{mg} / \mathrm{dl}$, LDL $>150 \mathrm{mg} / \mathrm{dl}, \mathrm{HDL}<40 \mathrm{mg} / \mathrm{dl}$, either in combination or alone. Thrombolysis was considered clinically successful if there was resolution of angina and or at least $50 \%$ reduction of ST-segment elevation 30 minutes to 1-hour post thrombolysis. Infarct territory and culprit vessel were identified on the basis of electrocardiogram and coronary angiogram respectively. Coronary artery disease severity in diameter stenosis was defined as mild $(<50)$, moderate $(50-70 \%)$, severe $(70-99 \%)$ and total occlusion (100\%). Quantitative Coronary Analysis (OCA) using standard philips software was used for quantification of stenosis severity. All procedures were performed via transfemoral or transradial route using 5 or $6 \mathrm{~F}$ systems. All patients received aspirin $150 \mathrm{mg}$ and clopidogrel $300 \mathrm{mg}$ orally immediately on arrival to the emergency department. Rescue $\mathrm{PCl}$ cases received additional $300 \mathrm{mg}$ of clopidogrel at the start of the procedure. Unfractionated heparin 50-70 U/kg bolus was given after $\mathrm{PCl}$ guide engagement. Use of Ilbllla receptor blockers (Eptifibatide or Tirofiban) was at the discretion of the operator. Those patients who had received low-molecular weight heparin (LMWH) in the emergency department did not receive additional heparin in the catheterization laboratory if the procedure was performed within 8 hours. Between 8-12 hrs, an additional $0.3 \mathrm{mg} / \mathrm{kg}$ IV bolus was given. Use of bare metal stents (BMS) or drug eluting stents (DES) was also at the discretion of the operator. Femoral sheaths were removed $4 \mathrm{hrs}$ after heparin bolus and manual femoral compression was used in all patients with $4 \mathrm{hrs}$ of bed rest after sheath removal. Radial bands (Terumo medical corporation, Japan) were used after transradial procedure using perfusion hemostasis technique. All patients received clopidogrel $75 \mathrm{mg}$ twice/day for 30 days followed by $75 \mathrm{mg} / \mathrm{d}$ for one year. Aspirin $150 \mathrm{mg} / \mathrm{d}$ was prescribed indefinitely. All patients received betablockers, angiotensive converting enzyme inhibitors (ACE-I)/angiotensin receptor blockers (ARB), statins and nitrates unless contraindicated. All patients had a one week, one month and three months clinical or telephonic follow-up. No patients were lost to follow-up. Major adverse cardiac events (MACE) were defined as new UA/NSTEMI, STEMI requiring target lesion revascularization (TLR), cardiogenic shock and cardiac death. Descriptive statistics were used to obtain percentages of multiple variables using SPSS v.17.

\section{RESULTS}

A total of 57 patients presenting with acute STEMI were included in the analysis. Table- 1 shows the baseline characteristics of the study sample. The mean age was $55 \pm 9.6$ years and $91 \%$ were male. 24 (42\%) patients had two risk factors for CAD and 18 (31\%) patients had three risk factors. More than half of the study population suffered an anterior $\mathrm{MI}$ and a third suffered an inferior MI. Streptokinase was used in 45 (79\%) patients cases with a failure rate of $18 \%$. Reteplase was used in $12(21 \%)$ and failed to reperfuse in one patient. All patients underwent coronary angiography at a mean interval of $16 \pm 4$ hours after thrombolysis. $\mathrm{PCl}$ of the infarct related vessel was performed in all subjects $(100 \%)$. Procedural success, defined as less than $50 \%$ residual stenosis in culprit vessel with TIMI-3 flow, was achieved in $100 \%$ of patients. Thrombus aspiration was performed in four patients, three of whom had failed thrombolysis with streptokinase while one had clinically successful thrombolysis before being taken for angiography. Ilbllla receptor blockers were used in a total of $11(19 \%)$ patients including $31(55 \%)$ cases of rescue $\mathrm{PCl}$. BMS were used in 14 (23\%) of patients and DES in $44(77 \%)$ patients. The angiographic characteristics of the study patients (Table 2). LAD was the culprit ves- 
sel in $32(56 \%)$ of the patients and RCA in 20 (35\%). Five patients had circumflex artery as the culprit vessel. Fifty six (99\%) patients had more than $70 \%$ diameter stenosis of the culprit vessel including four patients who had $100 \%$ occlusion of the infarct vessel. Only one patient had between 50-70 \% diameter stenosis of the culprit vessel on QCA. Out of the four patients with $100 \%$ occlusion, only one underwent rescue $\mathrm{PCl}$. The other three had clinically successful thombolysis. Fifteen (26\%) patients had two-vessel CAD and 11 (19\%) patients had triple vessel CAD. There were no major bleeding complications or in-hospital MACE. At three months follow-up, only one patient had MACE (Stent thrombosis of infarct vessel) requiring emergent $\mathrm{PCl}$ (Table 3).

Table 1. Baseline Characteristics.

\begin{tabular}{ll} 
Particular & $\mathrm{n}(\%)$ \\
\hline Age (mean \pm SD ) & $55.3 \pm 9.6$ \\
\hline Male & $52(91.2 \%)$ \\
\hline Female & $5(8.8 \%)$ \\
\hline Hypertension & $22(38.6 \%)$ \\
\hline Tobacco History & $33(57.9 \%)$ \\
\hline Dyslipidemia & $12(21.1 \%)$ \\
\hline Diabetes Mellitus & $20(35.1 \%)$ \\
\hline Two Risk Factors & $24(42.1 \%)$ \\
\hline Three Risk Factors & $18(31.6 \%)$ \\
\hline LVEF* ${ }^{*} 35 \%$ & $7(12.3 \%)$ \\
\hline Streptokinase & $45(78.9 \%)$ \\
\hline Reteplase & $12(21.1 \%)$ \\
\hline Successful Thrombolysis & $48(84.2 \%)$ \\
\hline Rescue PCl $\dagger$ & $9(15.8 \%)$ \\
\hline Access site & \\
\hline Transfemoral & $50(87.7 \%)$ \\
\hline Transradial & $7(12.3 \%)$ \\
\hline Location Of & \\
Infarction & $32(56.1 \%)$ \\
\hline Anterior & $20(35.1 \%)$ \\
\hline Inferior & \\
\hline Lateral & \\
\hline
\end{tabular}

*LVEF: Left Ventricular Ejection Fraction, †PCI: percutaneous coronary intervention
Table 2. Angiographic Findings.

\begin{tabular}{lllll}
\hline Infarct vessel & \multicolumn{2}{l}{ Severity of stenosis } & Total \\
& $51-70 \%$ & $71-99 \%$ & $100 \%$ & \\
$\mathrm{n} \mathrm{(57)}$ & 0 & 31 & 1 & 32 \\
$\begin{array}{l}\text { Left Anterior } \\
\text { Descending }\end{array}$ & & & \\
$\begin{array}{l}\text { Artery } \\
\text { Right Coronary }\end{array}$ & 1 & 17 & 2 & 20 \\
$\begin{array}{l}\text { Artery } \\
\text { Left Circumflex }\end{array}$ & 0 & 4 & 1 & 5 \\
Artery & & & & \\
\hline
\end{tabular}

Table 3. MACE at three Months Follow Up.

\begin{tabular}{ll}
\hline Particulars & $\mathbf{n}(\%)$ \\
\hline Unstable Angina & 0 \\
NSTEMI & $1(1.8 \%)$ \\
STEMI & 0 \\
Cardiac Death & 0 \\
Cardiogenic Shock & 0 \\
\hline Repeat Revascularization & $1(1.8 \%)$ \\
Infarct Vessel & 0 \\
\hline Non-infarct Vessel & $1(1.8 \%)$ \\
\hline Stent Thrombosis & \\
\hline
\end{tabular}

\section{DISCUSSION}

While disruption of a rich lipid-core atherosclerotic plaque is well established as the critical event in the pathogenesis of ACS. ${ }^{7,8}$ It has generally been thought that the culprit vessel in ACS often has only mild-moderate underlying disease. However this has been based on several small scale studies. ${ }^{1,2,9}$ Hackett et al looked at residual stenosis in 60 patients after successfully thrombolysis and found $47 \%$ patients with less than $60 \%$ diameter stenosis in the culprit vessel. ${ }^{10}$ More recently, several larger scale prospective studies have shown that the majority of patients with ACS have severe disease in the culprit vessel. ${ }^{11}$ Frobert and colleagues recently looked at 250 patients presenting with acute myocardial infarction and found that $96 \%$ had more than $50 \%$ stenosis severity and $66 \%$ had more than $70 \%$ stenosis severity by angiography. ${ }^{12}$ They concluded that in the majority of patients presenting with STEMI, the underlying stenosis in the culprit vessel is severe. They performed primary $\mathrm{PCl}$ in all patients. In another recent study, Chan et al looked at angiographic findings in 203 patients with STEMI. They found that $78 \%$ patients had more than $50 \%$ stenosis and $31 \%$ 
had more than $70 \%$ stenosis on QCA. They also concluded that in patients with STEMI, there was a strong relationship between stenosis severity and infarct related lesions. ${ }^{13}$ We had anecdotal experience in our practice that most STEMI patients undergoing coronary angiography had more than $70 \%$ stenosis and almost always required subsequent $\mathrm{PCl}$ regardless of whether thrombolysis was successful or not. Our current study confirms these observations which have major clinical implications. Because of financial constraints and non-availability of $\mathrm{PCl}$ in most public sector hospitals in Pakistan, thrombolysis for STEMI remains the primary therapy. In successful cases, it is generally assumed that the underlying disease is likely mild-moderate and will not require subsequent $\mathrm{PCl}$. However, our present data, which is in agreement with recent studies, clearly shows that the underlying disease in $99 \%$ of patients was indeed severe i.e. 71-99\% diameter stenosis and one should have a very low threshold for performing coronary angiography if there is any episode of recurrent angina. Verheught et al have already shown that after successful thombolysis, the early in-hospital reocclusion rate is as much as $10 \%$ and increasing to $30 \%$ at three months. ${ }^{14}$ Since activation of the thombotic cascade remains a serious problem in the setting of an acute STEMI, the recent wide spread availability of both oral and intravenous antiplatelets and anticoagulants has significantly increased the efficacy and safety of early $\mathrm{PCl}$ in this population. Even though the latest guidelines of the American College of Cardiology/ American Heart Association do not recommend routine coronary angiography, in the absence of recurrent angina after thrombolysis for STEMI, they do note that most hospital are increasingly performing routine coronary angiography and revascularization. ${ }^{15}$ One year after the updated guidelines were published, DiMario et al showed in a randomized trial of 600 patients that routine early angiography and revascularization significantly improved outcome in patients with STEMI as compared to symptom guided coronary angiography. ${ }^{16}$ This trend has recently been provided further credibility in a study by Cantor et al who performed a large scale randomized trial in which they randomized patients presenting with STEMI to routine care or early transfer and $\mathrm{PCl}$ within six hours after fibrinolysis. They found that early coronary angiography and $\mathrm{PCl}$ was associated with significantly fewer ischemic complications than routine care. ${ }^{17}$ Based on recent reviews, it appears that the ideal time for performing routine coronary angiography and $\mathrm{PCl}$ is between 3-24 hrs, as performing $\mathrm{PCl}$ earlier than three hours is associated with more bleeding complications and delaying more than $24 \mathrm{hrs}$ may be associated with more re-occlusion cases. ${ }^{18}$

To our knowledge, this is the first study from South Asia looking at this perspective. Although our sample size was limited, but it was at par with similar studies. ${ }^{10}$ The cardiovascular risk equivalents of carotid artery disease and peripheral vascular disease were not accounted for in the risk factor group. Similarly incidence of Stroke/Transient Ischemic Attack was not assessed in the outcome group. Likewise the adherence of patients to medications and lifestyle modification was not taken into account when assessing MACE at 90 days. Although primary percutaneous intervention is now considered the gold standard reperfusion strategy for acute STEMI, primary thrombolysis still remains the cornerstone strategy at most centers in the developing world due to economic and technical constraints.

\section{CONCLUSION}

Our study suggests that despite clinically successful thrombolysis, the underlying coronary artery disease remains significant in majority of the acute STEMI cases. These findings mandate that routine coronary angiography should be offered to all patients even after clinically successful thrombolysis for STEMI as this can have major implications for both short and long term care. However, these findings need to be confirmed in a larger study before such recommendations can be made.

\section{REFERENCES}

1. Ambrose JA, Tannenbaum MA, Alexopoulos D, Hjemdahl-Monsen CE, Leavy J, Weiss M et al. Angiographic progression of coronary artery disease and the development of myocardial infarction. J Am Coll Cardiol. 1988;12:56-62.

2. Ambrose JA, Winters SL, Arora RR, Haft JI, Goldstein J, Rentrop KP, et al. Coronary angiographic morphology in myocardial infarction: a link between the pathogenesis of unstable angina and myocardial infarction. J Am Coll Cardiol. 1985;6:1233-8.
3. Gorlin R, Fuster V, Ambrose JA. Anatomic-physiologic link between acute coronary syndromes. Circulation. 1986;74:6-9.

4. Alderman EL, Corley SD, Fisher LD, Chaitman BR, Faxon DP, Foster ED et al. Five-year angiographic follow-up of factors associated with progression of coronary artery disease in the Coronary Artery Surgery Study (CASS). J Am Coll Cardiol. 1993;22:1141-54.

5. Abizaid AS, Mintz GS, Mehran R, Abizaid A, Lansky AJ, Pichard AD et al. Long-term follow-up after percutaneous transluminal coronary angioplasty was not performed based on intravascular ultrasound findings: Importance of lumen dimensions. Circulation. 1999;100:256-61. 
6. Pijls NH, Van SP, Manoharan G, Boersma E, Bech JW, Veer $\mathrm{M}$ et al. Percutanous coronary intervention of functionally non-significant stenosis: 5-year Follow-up of the DEFER study. J Am Coll Cardiol. 2007; 49:2105-11.

7. Rioufol G, Finet G, Ginon I, André-Fouët X, Rossi R, Vialle $\mathrm{E}$ et al. Multiple atherosclerotic plaque rupture in acute coronary syndrome: a three-vessel intravascular ultrasound study. Circulation. 2002;106:804-8.

8. Shah PK. Mechanism of plaque vulnerability and rupture. J Am Coll Cardiol. 2003;41:15S-22S.

9. Little WC, Constantinescu M, Applegate RJ, Kutcher MA, Burrows MT, Kahl FR et al. Can coronary angiography predict the site of a subsequent myocardial infarction in patients with mild-to-moderate coronary artery disease? Circulation. 1988;78:1157-66.

10. Hackett D, Davies G, Maseri A. Pre-existing coronary stenoses in patients with first myocardial infarction are not necessarily severe. Eur Heart J. 1988;9:1317-23.

11. Nobuyoshi M, Tanaka M, Nosaka H, Kimura T, Yokoi H, Hamasaki $\mathrm{N}$ et al. Progression of coronary atherosclerosis: is coronary spasm related to progression? J Am Coll Cardiol. 1991;18:904-10.

12. Frøbert O, van't Veer M, Aarnoudse W, Simonsen U, Koolen JJ, Pijls NH. Acute myocardial infarction and underlying stenosis severity. Catheter Cardiovasc Interv. 2007 Dec 1;70(7):958-65.

13. Chan KH, Chawantanpipat C, Gattorna T, Chantadansuwan T, Kirby A, Madden A, Keech A, Ng MK. The relationship between coronary stenosis severity and compression type coronary artery movement in acute myocardial infarction. Am Heart J. 2010 Apr;159(4):584-92.

14. Verheugt FW, Meijer A, Lagrand WK, Van Eenige MJ. Reocclusion, the flipside of coronary thrombolysis. J Am Coll Cardiol. 1996;27:766-73.

15. Kushner FG, Hand M, Smith SC Jr, King SB 3rd, Anderson JL, Antman EM et al. 2009 focused updates: ACC/AHA guidelines for the management of patients with ST-elevation myocardial infarction (updating the 2004 guideline and 2007 focused update) and ACC/AHA/SCAI guidelines on percutaneous coronary intervention (updating the 2005 guideline and 2007 focused update) a report of the American College of Cardiology Foundation/American Heart Association Task Force on Practice Guidelines.J Am Coll Cardiol. 2009 Dec 1;54(23):2205-41.

16. Di Mario C, Dudek D, Piscione F, Mielecki W, Savonitto $\mathrm{S}$, Murena $\mathrm{E}$ et al. Immediate angioplasty versus standard therapy with rescue angioplasty after Thrombolysis in the combined Abciximab Reteplase Stent Study in Acute Myocardial Infarction (CARESS-in-AMI): an open, prospective, randomized, multicentre trial. Lancet. 2008;371:559-68.

17. Cantor WJ, Fitchett D, Borgundvaag B, Ducas J, Heffernan M, Cohen EA et al. Routine Early Angioplasty after Fibrinolysis for Acute Myocardial Infarction. N Eng J Med. 2009;360:2705-18.

18. Verheught FW. Timing of angiography after fibrinolysis for ST-elevation acute myocardial infarction. Curr Opin Cardiol. 2010;25:302-4. 